\title{
Differences in cardiorespiratory responses of young and senior male endurance athletes to maximal graded exercise test
}

\author{
M. MICHALIS ${ }^{1}$, K.J. FINN ${ }^{2}$, R. PODSTAWSKI ${ }^{3}$, S. GABNAI $^{4}$, Á. KOLLER ${ }^{5}$, \\ A. CZIRÁKI ${ }^{6}$, M. SZÁNTÓ ${ }^{6}$, Z. ALFÖLDI ${ }^{7}$ and F. IHÁSZ ${ }^{4 *}$
}

${ }^{1}$ Doctoral School, University of Physical Education, Budapest, Hungary

${ }^{2}$ School of Nutrition, Kinesiology, \& Psychological Sciences, College of Health, Science and Technology, University of Central Missouri, Warrensburg, MO, USA

${ }^{3}$ Faculty of Environmental Sciences Chair of Tourism, Recreation and Ecology, University of Warmia and Mazury in Olsztyn, Olsztyn, Poland

${ }^{4}$ Department of Sport Sciences, Faculty of Education and Psychology, Eötvös Loránd University, Szombathely, Hungary

${ }^{5}$ Sport Physiology Research Center, University of Physical Education, Budapest, Hungary

${ }^{6}$ Heart Institute, Clinical Center, University of Pécs, Pécs, Hungary

${ }^{7}$ Doctoral School of Health Sciences, University of Pécs, Pécs, Hungary

Received: March 31, 2020 • Accepted: July 6, 2020

Published online: September 29, 2020

(c) 2020 The Author(s)

\section{ABSTRACT}

Within recent years the popularity of sportive activities amongst older people, particularly competitive activities within certain age groups has increased. The purpose of this study was to assess the differences in the cardiorespiratory output at anaerobic threshold and at maximal power, output during an incremental exercise, among senior and young athletes. Ten elderly male subjects [mean (SD) age: $68.45 \pm 9.32$ years] and eight young male subjects [mean (SD) age: $25.87 \pm 5.87$ years] performed an incremental exercise test on a treadmill ergometer. No significant differences in body size were evident; however, the differences between the groups for peak power $(451.62 \pm 49$ vs. $172.4 \pm 32.2 \mathrm{~W})$, aerobic capacity $(57.97 \pm 7.5$ vs. $\left.40.36 \pm 8.6 \mathrm{~mL} \mathrm{~kg}^{-1} \mathrm{~min}^{-1}\right)$, maximal heart rate $\left(190.87 \pm 9.2\right.$ vs. $158.5 \pm 9.1$ beats $\left.\mathrm{min}^{-1}\right)$, peak blood

* Corresponding author. Faculty of Pedagogy and Psychology, Department of Sport Sciences, Eötvös Loránd University, Károlyi Gáspár square, 9700 Szombathely, Hungary. Tel.: +36 3053220 20. E-mail: ihasz.ferenc@ppk.elte.hu 
lactate $\left(11 \pm 1.7\right.$ vs. $\left.7.3 \pm 1.4 \mathrm{mmol} \mathrm{L}^{-1}\right)$, and $\% \mathrm{VO}_{2 \max }$ at ventilatory thresholds $(93.18 \pm 4.3$ vs. $79.29 \pm$ 9.9\%) were significantly lower in the senior athletes. The power output at anaerobic threshold was also higher $(392 \pm 48$ vs. $151 \pm 23 \mathrm{~W})$ in the young athletes, explaining the significant difference in terms of performance between these groups. We have observed an evident deterioration in some of the cardiovascular parameters; however, the submaximal exercise economy seems to be preserved with aging. Exercise economy (i.e. metabolic cost of sustained submaximal exercise) was not different considerably with age in endurance-trained adults.

\section{KEYWORDS}

senior athletes, running economy, "exceptionally successful aging" metabolic cost

\section{INTRODUCTION}

Demographics in the world population is undergoing a continuous change; the current rate of people over the age of 65 years at $6.9 \%$ is expected to rise up to $19.3 \%$ by the year 2050 . This is a compelling change within this adult sub-demographic, because there can be a lot of older adults found to possess highly exclusive physiological attributes, a phenotype termed as "exceptionally successful aging" [1].

Physiological functional capacity (PFC) is defined (AHA, 2001) here as the ability to perform the physical tasks/work of daily life and the ease with which these tasks can be performed. At some point PFC declines with advancing age even in healthy adults, resulting in a reduced capacity to perform certain physical work/tasks. This can eventually result in increased incidence of functional disability, increased use of health care services, loss of independence, and reduced quality of life [2-3]. To ensure we recognize successful aging, we need to understand the changes due to aging alone rather than health-related declines in PFC due to disease, disability, or physical inactivity.

In general, distance-running performance begins to decline around the age of 35 years. A prime reason for this decline in performance is the diminution of aerobic capacity $\left(\mathrm{VO}_{2 \max }\right)$ [4]. Hollenberg et al. [5] suggested the decline in maximal heart rate as longitudinal changes in older adults which explains reduction in aerobic capacity. Additionally, Fleg et al. [6] identified oxygen pulse (ratio of $\mathrm{VO}_{2}$ to heart rate) affected by age in a longitudinal study of healthy adults.

Other factors, however, also contribute to endurance performance. The point in which blood lactate accumulates, historically referred to as the Anaerobic Threshold has been suggested as a limiting factor in sustaining endurance performance [7]. Since blood lactate accumulation (BLa) is based on the rate of lactate production exceeding lactate clearance, the respiratory gas exchange ratio $\left(\mathrm{VCO}_{2} / \mathrm{VO}_{2}\right)$ can be viewed as a reflection of this point during incremental exercise. Running economy (RE), which is measured as the energy expended during endurance performance has also been recognized as a contributing factor to endurance performance [8]. The rate of oxygen consumption $\left(\mathrm{VO}_{2}\right)$ at different running velocities can describe energy contribution. High consumption at a low speed suggests poor economy [9]. Therefore, to account for aging-related declines in PFC, there is a need to study the determinants of endurance performance. If senior athletes continue to compete, they could be used as a suitable comparative group, in which we could observe the effects of aging in healthy adults. 
Senior endurance athletes provide a suitable comparative group in which to distinguish. In senior endurance athletes we expect less endurance performance as compared to young endurance athletes, although these differences are not so significant if the athlete continues to train. Specifically, we assume that if senior athletes were to continue to train, the aging-related decline in aerobic capacity (caused by the decrease of cardiac output) would be less significant.

\section{Aim of the study and hypotheses}

The primary aims of this study were to assess, during maximal incremental exercise, the differences in the cardiorespiratory responses of young and senior athletes at anaerobic threshold and maximal exercise. On the basis of past studies, we hypothesized that, compared to young athletes, maximal exercise power will be reduced in senior athletes due to reduced cardiorespiratory variables (such as pulmonary ventilation (VE), oxygen uptake $\left(\mathrm{VO}_{2}\right), \mathrm{VO}_{2 \max }$, expired carbon dioxide $\left(\mathrm{VCO}_{2}\right)$, and respiratory exchange ratio (RER)). It is hypothesized that the power output at anaerobic threshold will also be lower with aging due to decreasing blood lactate levels and running economy, which affect the athletes' ability to sustain endurance performance.

\section{MATERIAL AND METHODS}

\section{Subjects}

Eight young, internationally known male triathlon athletes who regularly attended competitions were recruited from the ELTE University Sports Club in Szombathely, Hungary. Ten senior male athletes (three road cyclists, five triathletes, and two marathon runners) were selected, who had been training regularly for at least the preceding 10 years and placed first, second, or third in regional, national, or international competition in running. Members of both groups were currently training five times a week, for one and a half hours per day. The young athletes (YA) were aged from 22 to 31 years $(25.87 \pm 5.87)$, whereas the senior athletes (SA) were aged from 59 to 72 years $(68.45 \pm 9.32)$. The Research and Ethics Board of the Eötvös Loránd University approved (2018/334) the written informed consent form for all subjects.

\section{Body composition estimation}

The InBody 720 (Biospace Co. Inc., Seoul, South Korea) Bioelectrical Impedance Analyzer (BIA) was used to determine body weight and body composition. Body height was measured with Sieber-Hegner instrument to the nearest $0.1 \mathrm{~cm}$ accuracy. In our work, we considered the procedural recommendations of the International Biological Program.

Body weight was measured with subjects wearing shorts and a lightweight shirt (no shoes or socks) and recorded in kilograms (kg). This foot-to-foot, hand-to-hand and hand-to-foot contact device uses two stainless-steel foot pad electrodes mounted on a platform scale and two stainless steel handles to allow for Tetrapolar 8-point tactile electrode system. From impedance measures for six electrical frequencies the lean body mass is estimated, which then is used to calculate the body fat percentage (BF\%). The reliability of bioelectrical-impedance analysis compared to other body composition measurement methods, like DXA, has been successfully demonstrated [10-12]. 


\section{Protocol}

All subjects were familiarized with the laboratory exercise tests. On arrival, they received standardized instructions as to the testing procedure. They underwent physical examinations, and resting electrocardiograms (ECGs) were taken. The two groups were measured on different days ( 2 days in between), and all experiments were done in the afternoon $(2-5 \mathrm{pm})$ at a laboratory temperature of approximately $20-22.8{ }^{\circ} \mathrm{C}$. The subjects were asked to abstain from physical exercise for one day before the experiment and from drinking caffeine beverages in the last $4 \mathrm{~h}$ preceding the test.

All participants had passed a medical examination and gave their informed written consent before participating in the study, following the legal requirements and the Declaration of Helsinki. We comply with the human and animal experimentation policy statements guidelines of the American College of Sports Medicine.

\section{Maximal graded exercise test}

$\mathrm{VO}_{2 \max }$ was measured during an incremental test on a treadmill (Life Fitness, model 95Te, United States) to volitional exhaustion, as previously described [18]. The test started at $5.0 \mathrm{~km} \mathrm{~h}^{-1}$ walk, the velocity was increased in $1.0 \mathrm{~km} \mathrm{~h}^{-1}$ every 2 min from $8.0-14.0 \mathrm{~km} \mathrm{~h}^{-1}$, then the inclination of the treadmill was increased $1.0 \%$ every $30 \mathrm{~s}$ until volitional fatigue. From the speed and inclination, a power conversion using the Jaeger formula was calculated for each stage of the incremental test. The Jaeger formula for running is: $\mathrm{W}$ [Watt] $=(\mathrm{v} \cdot \mathrm{BW} \cdot(2.11+$ $\mathrm{G} \cdot 0.25)+2.2 \cdot \mathrm{BW}-151) 10.5^{-1}$ where $\mathrm{BW}=$ body weight $(\mathrm{kg}), \mathrm{v}=$ velocity $\left(\mathrm{km} \mathrm{h}^{-1}\right), \mathrm{G}=$ gradient (\%). The total time of the test is reported as Load (in seconds) in the results.

Gas exchange was recorded continuously with a portable breath-to-breath gas analyzer (K4b2, Cosmed, Italy). The analyzer was calibrated according to the manufacturer's instructions prior to each trial run. $\mathrm{VE}, \mathrm{VO}_{2}, \mathrm{VCO}_{2}$, and RER were averaged over $10 \mathrm{~s}$ periods, with the highest $30 \mathrm{~s}$ value (i.e., three consecutive $10 \mathrm{~s}$ periods) used in the analysis. $\mathrm{VO}_{2 \max }$ was determined according to achievement of previously established criteria [13]: $\mathrm{VO}_{2}$ plateau (increase $<150 \mathrm{~mL} \mathrm{m^{-1 }}$ ), RER $>1.1$, and $\geq 90 \%$ of theoretical maximal heart rate $\left(\mathrm{HR}_{\max }\right)$. $\mathrm{VO}_{2 \max }$ was expressed in both absolute values $\left(\mathrm{L} \mathrm{min}^{-1}\right)$ and relative to body mass $\left(\mathrm{mL} \mathrm{kg}^{-1}\right.$ $\left.\min ^{-1}\right)$.

Running Economy (RE) was calculated from the data obtained using the method described by Millet and Bentley [14]. For this calculation, the speed of the treadmill at $14.0 \mathrm{~km} \mathrm{~h}^{-1}$ was used in the equation $=\left(\mathrm{VO}_{2}-0.083\right) \mathrm{V}^{-1}$, where $\mathrm{VO}_{2}$ is expressed in $\mathrm{mL} \mathrm{kg}^{-1} \mathrm{~s}^{-1} ; 0.083 \mathrm{~mL}$ $\mathrm{kg}^{-1} \mathrm{~s}^{-1}$ is the resting metabolic rate in young adults and $\mathrm{V}$ is the mean velocity of the treadmill in $\mathrm{m} \mathrm{s}^{-1}$. This method was used since it had been shown to be useful in comparing the energy cost of running to cycling in triathletes.

Anaerobic threshold (AT) was determined after completion of the exercise test; AT was determined for each subject using the $\mathrm{V}$-slope method of Beaver et al. [15]. This method involves the analysis of the response of $\mathrm{VCO}_{2}$ relative to $\mathrm{VO}_{2}$, and assumes that the threshold corresponds to the breakpoint in the $\mathrm{VCO}_{2} / \mathrm{VO}_{2}$ relationship. The reading was assessed independently by two experienced investigators. In the rare case of discordance, the criteria of Wasserman et al. [16] were used to reach a consensus or to eliminate the subject.

Heart rate (HR) in beats per minute was measured using a Polar H7 Bluetooth 4.0 Smart chest band heart rate transmitter while running, which was integrated into the metabolic system 
so that these data were recorded at each stage of the test. The HR values were used to identify maximal heart rate and the rate at the level of AT. From these measures, oxygen pulse, an indirect indicator of stroke volume, was determined using the formula VO2 (in liters per minute) divided by HR (in beats per minute).

Lactate was measured from a $400 \mu \mathrm{L}$ whole blood venipuncture sample taken 2 min after the end the treadmill test. A smaller sample $(3 \mu \mathrm{L})$ was placed on a reagent strip and inserted into the LactatePro 2 analyzer (Arkray, Kyoto, Japan). The lactate values were displayed within $15 \mathrm{~s}$ and recorded as venous lactate concentration in $\mathrm{mmol} \mathrm{L}^{-1}$.

\section{Statistical analysis}

Data for each group are expressed as the mean (SD). Comparison of the anthropometric and body composition characteristics of the groups was done by an independent $T$-test. Differences between the maximal values and those at the level of anaerobic threshold within groups were tested using a dependent $t$-test. Finally, the difference (delta) in variables measured both at the level of anaerobic threshold and maximal exercise between groups were tested using independent $T$-tests. Results were considered to be statistically significant if $P<0.05$.

\section{RESULTS}

The young (YA) and senior athletes' groups (SA) were not significantly different in terms of body weight $(\mathrm{BW})$ and body height $(\mathrm{BH})$ (Table 1). The senior athletes, however, had significantly higher percentage body fat mass and training history.

\section{Physiological responses in treadmill ergometer}

The physiological results of the subjects during the running portion of the testing are shown in Table 2. The young athletes had significantly higher results in each selected data than their older counterparts. Mean aerobic capacities (both absolute and relative) and maximal heart rates were significantly higher in the young group versus the senior group. The differences between the ventilatory thresholds of the groups were significant: young athletes $\mathrm{VT}\left(\% \mathrm{VO}_{2 \max }\right)_{\mathrm{YA}}=93.18$ \pm 4.3 , senior athletes $\mathrm{VT}\left(\% \mathrm{VO}_{2 \max }\right)_{\mathrm{SA}}=79.29 \pm 9.9$ percent, $P<0.001$. Similar results were obtained with regard to Running Economy (RE), maximal exercise peak power output (PPO), and relative power (RPPO), which were significantly higher in young men than in elderly men.

Table 1. Selected characteristics (age, $\mathrm{BH}, \mathrm{BW}, \% \mathrm{BFM}$ ) and Training history (TH) of the young (YA) and senior (SA) athletes

\begin{tabular}{lcc}
\hline Variables & YA. $(n=8)$ & SA. $(n=10)$ \\
\hline Age $(\mathrm{y})$ & $24.87 \pm 5.87$ & $68.45 \pm 9.32^{* *}$ \\
BH $(\mathrm{cm})$ & $178.75 \pm 7.30$ & $174.55 \pm 6.30$ \\
BW $(\mathrm{kg})$ & $72.81 \pm 7.47$ & $75.84 \pm 7.72$ \\
BF\% & $13.30 \pm 3.28$ & $17.80 \pm 2.39^{* *}$ \\
Training history (y) & $10.00 \pm 4.65$ & $18.20 \pm 2.34^{* *}$ \\
\hline
\end{tabular}

Abbreviations: Age (year), BH: body height, $\mathrm{BW}$ : body weight, BF\%: body fat percentage, Training history (year). ${ }^{* *}=P<0.01$. 
Table 2. Physiological variables obtained from the running portion of the laboratory test for the senior and young endurance athletes

\begin{tabular}{|c|c|c|}
\hline Variables & Young A. $(n=8)$ & Senior A. $(n=10)$ \\
\hline $\mathrm{VO}_{2 \max }\left(\mathrm{L} \min ^{-1}\right)$ & $4.25 \pm 0.3$ & $3.24 \pm 0.4^{* *}$ \\
\hline $\mathrm{RVO}_{2 \max }\left(\mathrm{mL} \mathrm{kg}^{-1} \min ^{-1}\right)$ & $57.97 \pm 7.5$ & $40.36 \pm 8.6^{* *}$ \\
\hline $\mathrm{HR}_{\max }\left(\right.$ beat $\left.\min ^{-1}\right)$ & $190.87 \pm 9.2$ & $158.5 \pm 9.1^{* * *}$ \\
\hline $\mathrm{PPO}(\mathrm{W})$ & $451.62 \pm 49$ & $172.4 \pm 32.2^{\star * *}$ \\
\hline $\mathrm{RPPO}\left(\mathrm{W} \mathrm{kg}^{-1}\right)$ & $6.28 \pm 1.1$ & $2.25 \pm 0.3^{\star * *}$ \\
\hline $\mathrm{VT}\left(\% \mathrm{VO}_{2 \max }\right)$ & $93.18 \pm 4.3$ & $79.29 \pm 9.9^{* *}$ \\
\hline Running Economy (RE); (W L ${ }^{-1} \min ^{-1}$ ) & $78.84 \pm 5.9$ & $41.7 \pm 1.6^{* *}$ \\
\hline
\end{tabular}

Abbreviations: $\mathrm{VO}_{2 \max }$ : aerobic capacity, $\mathrm{RVO}_{2 \max }$ : relative aerobic capacity, $\mathrm{HR}_{\text {max }}$ : maximal heart rate, PPO: peak power output, RPPO: relative peak power output. ${ }^{\star *}=P<0.01$, ${ }^{\star * \star}=P<0.001$.

Table 3 represents various measures at the anaerobic threshold and maximal exercise for each group including oxygen pulse $\left(\mathrm{O}_{2} \mathrm{P}\right)$, rate of carbon dioxide production $\left(\mathrm{VCO}_{2}\right)$, ventilation (VE), BLa, tidal volume (Vt), and breathing frequency $(\mathrm{BF})$. At the level of anaerobic threshold, ventilatory equivalent of oxygen $\left(\mathrm{VE} / \mathrm{VO}_{2}\right)$ and carbon dioxide $\left(\mathrm{VE} / \mathrm{VCO}_{2}\right)$ are presented.

Table 3. Descriptive data at anaerobic threshold (AT) and maximal exercise (ME), obtained in senior (SA) and young (YA) groups

\begin{tabular}{|c|c|c|}
\hline Variables & YA mean $\pm \operatorname{SD}(n=8)$ & $\mathrm{SA}$ mean $\pm \mathrm{SD}(n=10)$ \\
\hline \multicolumn{3}{|l|}{ Maximal exercise } \\
\hline Power (W) & $452 \pm 49$ & $172 \pm 32^{\star \star *}$ \\
\hline HRmax (beat $\min ^{-1}$ ) & $191 \pm 9$ & $159 \pm 9^{* * *}$ \\
\hline $\mathrm{O}_{2} \mathrm{P}\left(\mathrm{mL}_{\text {beast }^{-1}}\right)$ & $23.4 \pm 2.2$ & $21.8 \pm 3.6$ \\
\hline $\mathrm{VO}_{2}\left(\mathrm{~L} \min ^{-1}\right)$ & $4.3 \pm 0.3$ & $3.3 \pm 0.4^{* *}$ \\
\hline $\mathrm{VCO}_{2}\left(\mathrm{~L} \min ^{-1}\right)$ & $4.8 \pm 0.4$ & $4.3 \pm 0.7$ \\
\hline $\mathrm{VE}\left(\mathrm{L} \min ^{-1}\right)$ & $149 \pm 17$ & $117 \pm 21^{* * *}$ \\
\hline $\mathrm{BLa}\left(\mathrm{mmol} \mathrm{L}^{-1}\right)$ & $11 \pm 1.7$ & $7.3 \pm 1.4^{* * *}$ \\
\hline $\mathrm{Vt}(\mathrm{L})$ & $2.9 \pm 0.3$ & $2.8 \pm 0.5$ \\
\hline $\mathrm{BF}\left(n\right.$. of breath $\left.\mathrm{min}^{-1}\right)$ & $54 \pm 6$ & $42 \pm 7^{* * *}$ \\
\hline \multicolumn{3}{|l|}{ Anaerobic threshold } \\
\hline Power (W) & $392 \pm 48$ & $151 \pm 23^{\star \star *}$ \\
\hline $\mathrm{HR}_{\max }\left(\right.$ beat $\min ^{-1}$ ) & $178 \pm 9$ & $153 \pm 9^{* * *}$ \\
\hline $\mathrm{O}_{2} \mathrm{P}(\mathrm{mL} \mathrm{min}-1)$ & $21.4 \pm 2.6$ & $19.5 \pm 3.3$ \\
\hline $\mathrm{VO}_{2}\left(\mathrm{~L} \mathrm{~min}^{-1}\right)$ & $3.73 \pm 0.4$ & $3.08 \pm 0.2^{\star *}$ \\
\hline $\mathrm{VCO}_{2}\left(\mathrm{~L} \min ^{-1}\right)$ & $4.01 \pm 0.4$ & $3.67 \pm 0.4$ \\
\hline $\mathrm{VE}\left(\mathrm{L} \min ^{-1}\right)$ & $125 \pm 22$ & $102 \pm 21^{* *}$ \\
\hline $\mathrm{VE} / \mathrm{VO}_{2}\left(\mathrm{~L} \mathrm{perc}^{-1}\right)$ & $34 \pm 4$ & $31 \pm 7$ \\
\hline $\mathrm{VE} / \mathrm{VCO}_{2}\left(\mathrm{~L}_{\mathrm{perc}}{ }^{-1}\right)$ & $30 \pm 4$ & $26 \pm 4^{*}$ \\
\hline $\mathrm{Vt}(\mathrm{L})$ & $2.5 \pm 0.2$ & $2.4 \pm 0.5$ \\
\hline $\mathrm{BF}\left(n\right.$. of breathing $\min ^{-1}$ ) & $44 \pm 6$ & $37 \pm 6^{*}$ \\
\hline
\end{tabular}

Abbreviations: $\left(\mathrm{VO}_{2}\right)$ Oxygen uptake, $\left(\mathrm{VCO}_{2}\right)$ carbon dioxide output, $(\mathrm{VE})$ ventilation, (BLa) blood lactate accumulation, $\mathrm{HR}_{\max }$ : maximal heart rate, $\mathrm{O}_{2} \mathrm{P}$ : oxygen pulse, $\mathrm{VO}_{2}$ : oxygen consumption, $\mathrm{VCO}_{2}$ : carbondioxide production, VE: ventilation, Vt: tidal volume. ${ }^{*}=P<0.05,{ }^{* *}=P<0.01,{ }^{* *}=P<0.001$. 
Table 4. Cardiorespiratory characteristics: intra-group differences and their percentage (\%) between maximal exercise and anaerobic threshold

\begin{tabular}{|c|c|c|}
\hline & $\Delta[\%]$ YA $(\mathrm{ME}-\mathrm{AT})$ & $\Delta[\%] \mathrm{SA}(\mathrm{ME}-\mathrm{AT})$ \\
\hline Power $(\mathrm{W})$ & $60[13]$ & $21[12]^{\star * *}$ \\
\hline Load (sec) & 161 [17] & $73[13]^{\star \star *}$ \\
\hline HR (beat $\min ^{-1}$ ) & $13[6]$ & $6[3]$ \\
\hline $\mathrm{O}_{2} \mathrm{P}\left(\mathrm{mL}\right.$ beat $\left.^{-1}\right)$ & $2[8]$ & $2,3[6]$ \\
\hline $\mathrm{VO}_{2}\left(\mathrm{~L} \min ^{-1}\right)$ & $0.6[13]$ & $0.4[16]^{* *}$ \\
\hline $\mathrm{VCO}_{2}\left(\mathrm{~L} \mathrm{~min}^{-1}\right)$ & $0.79[16]$ & $0.63[14]^{\star *}$ \\
\hline $\mathrm{VE}\left(\mathrm{L} \min ^{-1}\right)$ & $24[16]$ & $15[12]^{\star *}$ \\
\hline $\mathrm{Vt}(\mathrm{L})$ & $0.3[10]$ & $0.4[14]$ \\
\hline $\mathrm{BF}$ (fr. of breathing $\min ^{-1}$ ) & $10[18]$ & $5[11]^{* * *}$ \\
\hline
\end{tabular}

Abbreviations: ME: maximal exercise, AT: anaerobic threshold, $\mathrm{HR}$ : heart rate, $\mathrm{O}_{2} \mathrm{P}$ : oxygen pulse, $\mathrm{VO}_{2}$ : oxygen consumption, $\mathrm{VCO}_{2}$ : carbon-dioxide production, VE: ventilation, VT: tidal volume, BF: breath frequency. ${ }^{\star}=P<0.05,{ }^{*}=P<0.01,{ }^{* *}=P<0.001$.

Significantly higher $\mathrm{VE}, \mathrm{BF}$, and $\mathrm{BLa}$ in the young men are evident at maximal exercise. The $\mathrm{VCO}_{2}, \mathrm{Vt}$, and $\mathrm{O}_{2} \mathrm{P}$ were not significantly different between groups. $\mathrm{VE}$ and $\mathrm{VE} / \mathrm{VCO} \mathrm{O}_{2}$ were significantly higher in young men compared to elderly men. No significant differences were observed between the two groups concerning the same characteristics at the anaerobic threshold (AT) and in the maximal exercise zone.

Table 4 reports the delta values $(\Delta)$ and percentages (\%) of the results in the two intensity levels, maximal exercise (ME) and AT within the groups ( $\mathrm{YA}_{\mathrm{ME}-\mathrm{AT}}$; $\left.\mathrm{SA}_{\mathrm{ME}-\mathrm{AT}}\right)$. The results of the independent $t$-test indicate the differences in Power, Load, $\mathrm{VO}_{2}, \mathrm{VCO}_{2}, \mathrm{VE}, \mathrm{Vt}$ and $\mathrm{BF}$ are significant between the groups. All significant differences had higher values in the young athlete group.

\section{DISCUSSION}

This study demonstrates a difference between young and senior endurance athletes in aerobic capacity and peak power both in absolute and relative units. In addition, the differences in maximal heart rate, percentage oxygen uptake at ventilatory threshold, and blood lactate reflect the lower measures in the older participants.

It is important to note, however, that on the same maximum exercise level there was no significant difference between the average oxygen pulses $\left(\mathrm{O}_{2} \mathrm{P}\right)$, carbon dioxide outputs $\left(\mathrm{VCO}_{2}\right)$ and tidal volumes $(\mathrm{Vt})$ of the two groups. Similarly, there was no significant difference over/at/ after the anaerobic threshold in the ventilatory equivalent for carbon dioxide $\left(\mathrm{VE} / \mathrm{VCO}_{2}\right)$ levels.

The power output from the anaerobic threshold (AT) to the maximum exercise level and the running time on the treadmill (Load) were significantly less in the senior athletes at approximately $30 \%$. There was no difference, however, between the average pulse intensities and the maximum pulse values of the two groups at AT. On the other hand, the differences between $\mathrm{VO}_{2}, \mathrm{VCO}_{2}$, ventilation and average respiratory rate values were three times higher in the senior athletes, whereas the differences in tidal volume $(\mathrm{Vt})$ and oxygen uptake $\left(\mathrm{VO}_{2 \max }\right)$ were five times higher in the senior than in young athletes when comparing the variables at AT.

Previous studies [16-18] have shown a 5-15\% reduction/decay in $\mathrm{VO}_{2 \max }$ when comparing men within the 20-75-year range. The results of these studies suggested that highly trained 
endurance athletes and average-trained fitness participants may have less than a 5\% decline/decay in $\mathrm{VO}_{2 \max }$ if the senior group continues with high-level training. In contrast, highly trained endurance athletes, who later become sedentary, have a greater than average reduction in $\mathrm{VO}_{2 \max }$ in older age. It is of note that part of the disparity in reports of the change and/or decline in $\mathrm{VO}_{2 \max }$ with age is related to whether the data had been collected in cross-sectional or longitudinal studies.

Other factors may contribute to age-associated reductions in endurance performance. Although the comparison is not straightforward because of different scaling and units, the fact that the rate of decline in endurance performance with age appears to be smaller than the corresponding fall in $\mathrm{VO}_{2 \max }$ [19] is consistent with this idea. It may be that other putative determinants of endurance performance (for example, 'anaerobic' muscular power, muscle capillary density, mitochondrial content, fiber types) may decline to a lesser extent with advancing age [20-21], thus offsetting the effects of the decrease in $\mathrm{VO}_{2 \max }$.

\section{Aerobic capacity}

$\mathrm{VO}_{2 \max }$ has an exact physiological definition that is expressed by the Fick equation: maximal cardiac output $\times$ maximal arterio-venous $\mathrm{O}_{2}$ difference. Within this physiological context, there is some controversy regarding the mechanisms responsible for the reduction in $\mathrm{VO}_{2 \max }$ with age in endurance athletes. In particular, the exact contribution of central (i.e. cardiac) and peripheral (i.e. oxygen extraction) factors to the reduced $\mathrm{VO}_{2 \max }$ in senior compared with young adult endurance athletes is unclear. However, it appears that decreases in both maximal cardiac output (Q) and maximal arterio-venous $\mathrm{O}_{2}$ difference may play a role [23]. For this study, maximal heart rate which was measured at maximal exertion was on the average significantly lower in the senior group. Maximal heart rate is expected to decline at a rate of 0.7 beats $\min ^{-1}$ year $^{-1}$ [22], which is what was observed in the mean group values for this study population. No other components in the Fick equation were measured, therefore we can only speculate on their influence in the measure of $\mathrm{VO}_{2 \max }$. From a cardiac output prospective, the stroke volume at maximal exercise would be suspect to play a major role in differences between these groups. If the oxygen pulse is reflective of stroke volume, then these results do not confirm a difference between these groups. Peripheral factors such as oxygen content in blood and rate of extraction might influence the differences between groups. We do not expect a significant change in hemoglobin content of blood or pulmonary diffusion between groups. The rate of extraction might be a factor if atrophy of fast oxidative glycolytic (FOG) muscle is present. This is a biological change due to aging, since these cells contribute to oxygen consumption during intense exertion. The lower lactate levels measured following the maximal test in the senior athletes suggest less lactate production in skeletal muscle while running, thus aging and its effect on muscle fiber availability should be considered in future studies.

\section{Respiratory responses}

This study showed a difference in maximal ventilation between groups due to reduction in breathing frequency rather than tidal volume. Since ventilation is related to oxygen uptake, it is possible that reduced oxygen uptake might have influenced breath rate using regulation from the expiratory control centers in the brain. Also, aging might have influenced the respiratory response. With increasing age, the lungs loose elastic recoil, the wall of the thorax becomes stiffer and more restricted, respiratory muscle function is impaired, the alveolar surface area is reduced and there is increased ventilation-perfusion heterogeneity [24]. These changes cause expiratory 
flow limitation and reduced gas diffusion capacity in elder subjects. Although there is a decline in the capacity for ventilation and gas exchange with age, there is also an age-related decline in the capacity of the other links of the oxygen uptake chain, thus reducing the demands on the respiratory system. The margin between demand and capacity in the respiratory system decreases with age, but limitation of $\mathrm{VO}_{2 \max }$ due to demands exceeding the capacity is thought to be rare.

\section{Metabolic background}

As suggested previously, there is higher catecholamine production in young athletes, and the fact that aging is associated with the attenuation of adrenergic stimulation during exercise [25] can also be important. The higher VE peaks of response may be explained by the higher $\mathrm{CO}_{2}$ of the young athletes and/or the hypothesized higher lactate level that may have contributed to the tendency of an increased end-of-recovery VE in young athletes.

However, the lactate threshold does not appear to change with increasing age when expressed relative to the percentage of $\mathrm{VO}_{2 \max }$ [26-27]. The latter finding suggests that the contribution of decreases in lactate threshold to reductions in endurance exercise performance with aging may be secondary to decreases in $\mathrm{VO}_{2 \max }$. Indeed, a recent longitudinal study of 51 male and 23 female Masters runners reported that the change in lactate threshold over a mean follow-up period of 6 years was not predictive of a corresponding change in running performance when it was expressed as a percent of $\mathrm{VO}_{2 \max }$ [28].

\section{Limitations of the study}

The sample size for this study limits the ability to generalize to larger groups. Since this study used selection criteria based upon training history (10 years prior) and current success in competition, and the ability to recruit beyond this region (western Hungary), we accept this limitation. A larger number of senior elite athletes might have added to external validity; however, in retrospect, a post-analyses calculation using the means and standard deviation of each groups' $\mathrm{VO}_{2 \max }$ (in relative units), we get a $17 \mathrm{~mL} \mathrm{~kg}{ }^{-1} \mathrm{~min}^{-1}$ decline in the seniors as compared to the young group which is $29.8 \%$ (17/57). Thus with 18 subjects we obtain a Cohen $\mathrm{d}$ (effect size) of 2.18249. Entering this effect size into a $t$-test analysis requires only 10 subjects to obtain a power of 0.80 . Future research is needed to confirm these results as well as to address the need to establish longitudinal analyses as middle-aged athletes begin to reach chronological ages which are thought to have the largest impact on physiological function.

Another limitation was the inability to report training volume using weekly load. While the young athletes made up a group from a university triathlon club, the seniors were selected based upon their history of training and their good performance in running competitions. Due to the variety of sports the seniors trained for, we had to hypothesize that the seniors' training was the same or at least similar to that of the young athletes.

\section{CONCLUSION}

In conclusion the available data indicate that decreases in $\mathrm{VO}_{2 \max }$ are the clearest and consistent contributor of these declines in performance. Reductions in the lactate levels may also contribute, whereas submaximal exercise economy is preserved with aging in endurance athletes [29]. The age-associated decreases in $\mathrm{VO}_{2 \max }$ in endurance exercise-trained adults are mediated 
by reductions in maximal cardiac output, with the heart rate contributing to the reduction for this study. The power levels of the seniors at the level of anaerobic threshold is also declined at a heart rate that is well below the maximal exercise value. These findings support the need to further understand the non-cardiac changes due to aging which reduce the sustainable work capacity. The socalled 'senior athlete model' continues to be a rich source of insight into our ability (or lack thereof) to understand performance declines and physiological function associated with human aging.

Funding: The study was completed with the support of the Hungarian Ministry of Human Capacities (ELTE Institutional Excellence Program, 783-3/2018/FEKUTSRAT).

Conflict of interest: All authors declare no conflict of interests.

Data availability: All the data can be acquired by reasonable request from the corresponding author.

\section{ACKNOWLEDGMENTS}

We would like to thank all the participants for their enthusiastic participation in the study.

\section{REFERENCES}

1. American Heart Association. Heart and stroke: statistical update. Dallas, TX: AHA; 2001.

2. Chick TW, Cagle TG, Vegas FA, Poliner JK, Murata GH. The effect of aging on submaximal exercise performance and recovery. J Gerontol Biol Sci 1991; 46: 34-8.

3. Coggan AR, Spina RJ, King DS, Rogers MA, Brown M, Nemeth PM, et al. Histochemical and enzymatic comparison of the gastrocnemius muscle of young and elderly men and women. J Gerontol 1992; 47: B71-6.

4. Coyle EF. Integration of the physiological factors determining endurance performance ability. Exerc Sport Sci Rev 1995; 23: 25-63.

5. Hollenberg M, Yang J, Haight TJ, Tager IB. Longitudinal changes in aerobic capacity: implications for concepts of aging. J Gerontol A Biol Sci Med Sci 2006; 61(8): 815-18.

6. Fleg JL, Morrell CH, Bos AG, Brant AG, Talbot LA, Wright JG, et al. Accelerated longitudinal decline of aerobic capacity in healthy older adults. Circulation 2005; 112(5): 674-82.

7. Coyle EF. Integration of the physiological factors determining endurance. Exerc Sport Sci Rev 1995; 23: 25-63.

8. Dempsey JA, Seals DR. Aging, exercise, and cardiopulmonary function. In: Lamb DR, Gisolfi CV, Nadel E, editors. Perspectives in exercise science and sports medicine. Exercise in older adults, Carmel, IN: Cooper; 1995. vol. 8, pp. 237-304.

9. Evans WJ. Effects of exercise on body composition and functional capacity of the elderly. J Gerontol 1995; 50A: $147-50$.

10. Gibson AL, Holmes JC, Desautels RL, Edmonds LB, Nuudi L. Ability of new octapolar bioimpedance spectroscopy analyzers to predict 4-component-model percentage body fat in Hispanic, black, and white adults. Am J Clin Nutr 2008; 87: 332-8. 
11. Howley ET, Bassett DR , Jr, Welch HG. Criteria for maximal oxygen uptake: review and commentary. Med Sci Sports Exerc 1995; 27(9): 1292-301.

12. Jackson AS, Beard EF, Wier LT, Ross RM, Stuteville JE, Blair SN. Changes in aerobic power of men, ages 2570 yr. Med Sci Sports Exerc 1995; 27: 113-20.

13. Janssens JP, Pache JC, Nicod LP. Physiological changes in respiratory function associated with ageing. Eur Respir J 1999; 13: 197-205.

14. Johnson BD, Dempsey JA. Demand vs. capacity in the aging pulmonary system. Exerc Sport Sci Rev 1991; 19: 171-210.

15. Beaver WL, Wasserman K, Whipp BJ. A new method for detecting anaerobic threshold by gas exchange. J Appl Physiol 1986; 60: 2020-7.

16. Wasserman K, Whipp B, Koyal SN, Beaver WL. Anaerobic threshold and respiratory gas exchange during exercise. J Appl Physiol 1973; 35(2): 236-43.

17. Joyner MJ. Physiological limiting factors and distance running: influence of gender and age on record performances. Exerc Sport Sci Rev 1993; 21: 103-33.

18. Kasch FW, Boyer JL, VanCamp S, Nettl F, Verity LS, Wallace JR. Cardiovascular changes with age and exercise: a 28-year longitudinal study. Scand J Med Sci Sports 1995; 5: 147-51.

19. Saunders PU, Pyne DB, Telford RD, Hawley JA. Reliability and variability of running economy in elite distance runners. Med Sci Sports Exerc 2004b; 36: 1972-6.

20. Schafer KJ, Siders WA, Johnson LK, Lukaski HC. Validity of segmental multiple-frequency bioelectrical impedance analysis to estimate body composition of adults across a range of body mass indexes. Nutrition 2009; 25: 25-32.

21. Shaw AJ, Ingham SA, Folland JP. The valid measurement of running economy in runners. Med Sci Sports Exerc 2014; 46: 1968-73.

22. Sun G, French CR, Martin GR, Younghusband B, Green RC, Xie YG, et al. Comparison of multifrequency bioelectrical impedance analysis with dual-energy X-ray absorptiometry for assessment of percentage body fat in a large, healthy population. Am J Clin Nutr 2005; 81: 74-8.

23. Tanaka H, Monahan KD, Seals DR. Age-predicted maximal heart rate revisited. J Am Coll Cardiol 2001; 37: 153-6.

24. Tanaka H, Seals DR. Endurance exercise performance in Masters athletes: age-associated changes and underlying physiological mechanisms. J Physiol 2008; 55: 55-63.

25. Trappe AW, Costil DL, Vukovich MD, Jones J, Melhom T. Aging among elite distance runners: a 22-yr longitudinal study. J Appl Physiol 1996; 80: 285-90.

26. Maffulli N, Testa V, Capasso G. Anaerobic threshold determination in master endurance runners. J Sports Med Phys Fitness 1994; 34: 242-9.

27. Evans SL, Davy KP, Stevenson ET, Seals DR. Physiological determinants of 10-km performance in highly trained female runners of different ages. J Appl Physiol 1995; 78: 1931-41.

28. Marcell TJ, Hawkins SA, Tarpenning KM, Hyslop DM, Wiswell RA. Longitudinal analysis of lactate threshold in male and female master athletes. Med Sci Sports Exerc 2003; 35: 810-17.

29. Tanaka H, Seals DR. Endurance exercise performance in Masters athletes: age-associated changes and underlying physiological mechanisms. J Physiol 2008; 586(Pt 1): 55-63.

Open Access. This is an open-access article distributed under the terms of the Creative Commons Attribution 4.0 International License (https://creativecommons.org/licenses/by/4.0/), which permits unrestricted use, distribution, and reproduction in any medium, provided the original author and source are credited, a link to the CC License is provided, and changes - if any - are indicated. (SID_1) 